\title{
UM MÊTODO PARA A AVALIAÇÃO DAS ATIVIDADES DE VÔO EM PLEBEIA SAIQUI (FRIESE) (HYMENOPTERA, MELIPONINAE)
}

\author{
MARIA AUGUSTA CABRAL DE OLIVEIRA \\ Departamento de Zoologia - Instituto de Biociências \\ da USP.
}

RESUMO

O presente trabalho descreve um método que determina qual o melhor intervalo de tempo de observação para uma avaliação da atividade de vôo em Plebeia saiqui.

A METHOD FROM EVALUATING FLIGHT ACTIVITY OF PLEBEIA SAIQUI (FRIESE) (HYMENOPTERA, MELIPONINAE)

\section{SUMMARY}

The present paper describes a practical method to choose the best observation time interval to assess the external flight activity of the meliponin - Plebeia saiqui.

\section{INTRODUÇÃO}

O conhecimento das atividades de vôo das abelhas é bastante importante, não só para um maior rendimento da apicultura e meliponicultura como também para o estudo do comportamento desses animais. Essa atividade poderia ser usada como um indicador das condições de coleta nos campos e das condições gerais da própria colônia.

A escolha da duração ideal de cada observação, de modo a se ter uma idéia geral e satisfatória da atividade da colônia, é um dos problemas fundamentais para os que pretendem estudar a atividade de vôo destes insetos.

Número especial em homenagem ao Prof. Dr. Paulo Sawaya, no ano jubilar de seu magistério. 
Devido as diferenças de comportamento e tamanho das populações, a duração das observações empregados por autores que trabalharam com Apis mellifera (Bondenheimer-BenNerya, 1933 e Gary, 1967a, entre outros) não dão resultados satisfatórios com $P$. saiqui. Em vista disso, empregamos o método descrito nesse trabalho, que poderá ser empregado para trabalhos semelhantes com outros meliponíneos.

\section{MATERIAL E MÉTODO}

As observações foram feitas em colônias de Plebeia saiqui. Foram usadas três colônias, uma das quais bastante fraca.

Contou-se, com auxílio de um contador manual, as abelhas que saiam das colmeias durante intervalos com durações de 1 , 2,5 e 10 minutos. Foram efetuadas 10 medidas para cada um destes períodos. As medidas foram feitas sempre em condições ambientais boas de luz, temperatura, umidade relativa e vento.

\section{RESULTADOS E DISCUSSÃO}

Os resultados obtidos estão apresentados nas Tabelas I, II e III.

Os resultados mostraram, como era de se esperar, que dentro de um mesmo intervalo, a variação entre uma contagem e outra é inversamente proporcional à duração das observações. Com base nestes dados foram calculados os erros experimentais (E) envolvidos nas determinações.

Pode-se verificar, nas Tabelas I e II, que as observações de 5 e 10 minutos de duração apresentaram um erro bem menor que as de 1 e 2 minutos. O Gráfico 1, feito com dados da Tabela I, permite uma melhor visualização da variação dos erros nos diferentes intervalos.

O objetivo do trabalho é determinar qual o melhor intervalo de tempo de observação para uma avaliação da atividade de vôo, verifica-se que os melhores intervalos são os de 5-10 minutos de observação. Nas colônias fortes a variação do erro nesses intervalos de observação é insignificante e por motivos práticos deve-se optar pelo intervalo mais curto. 


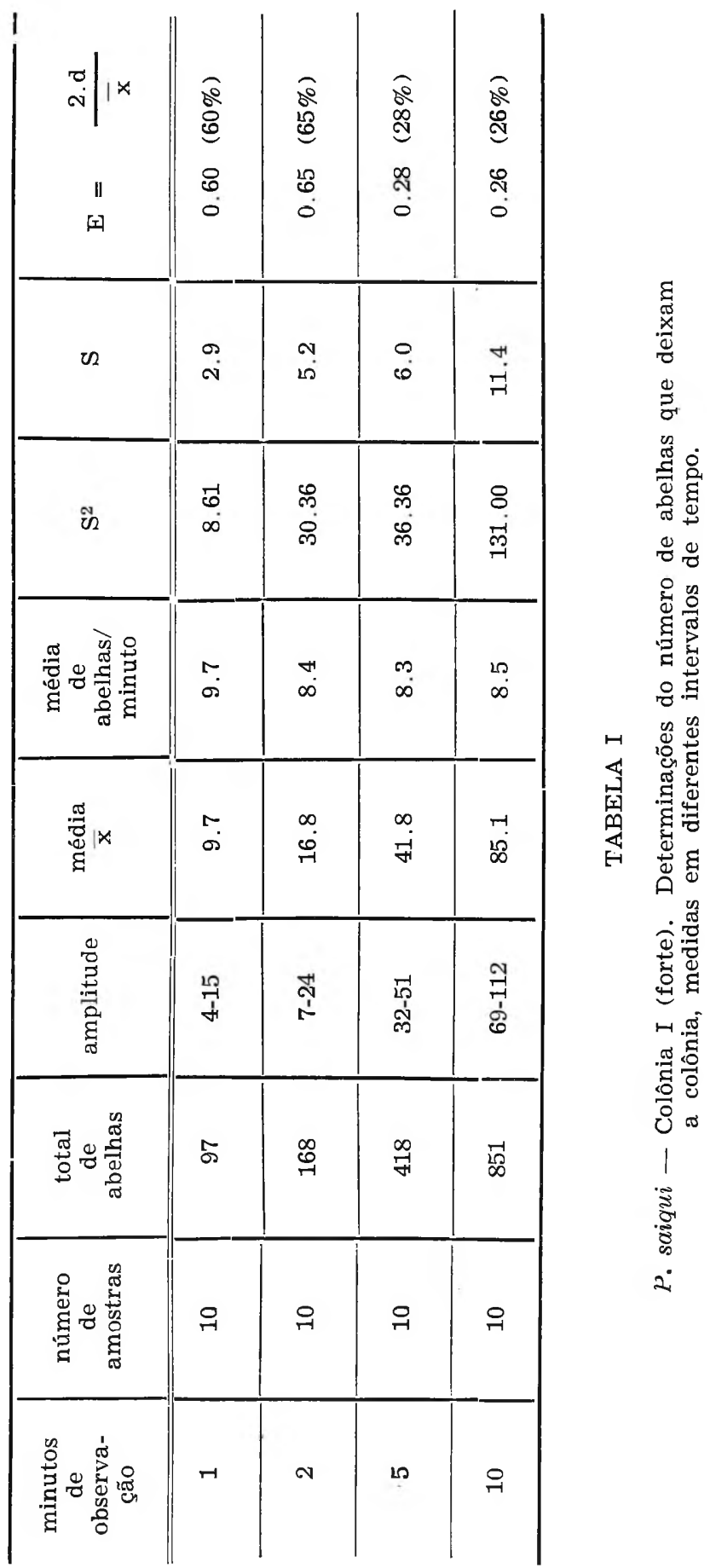




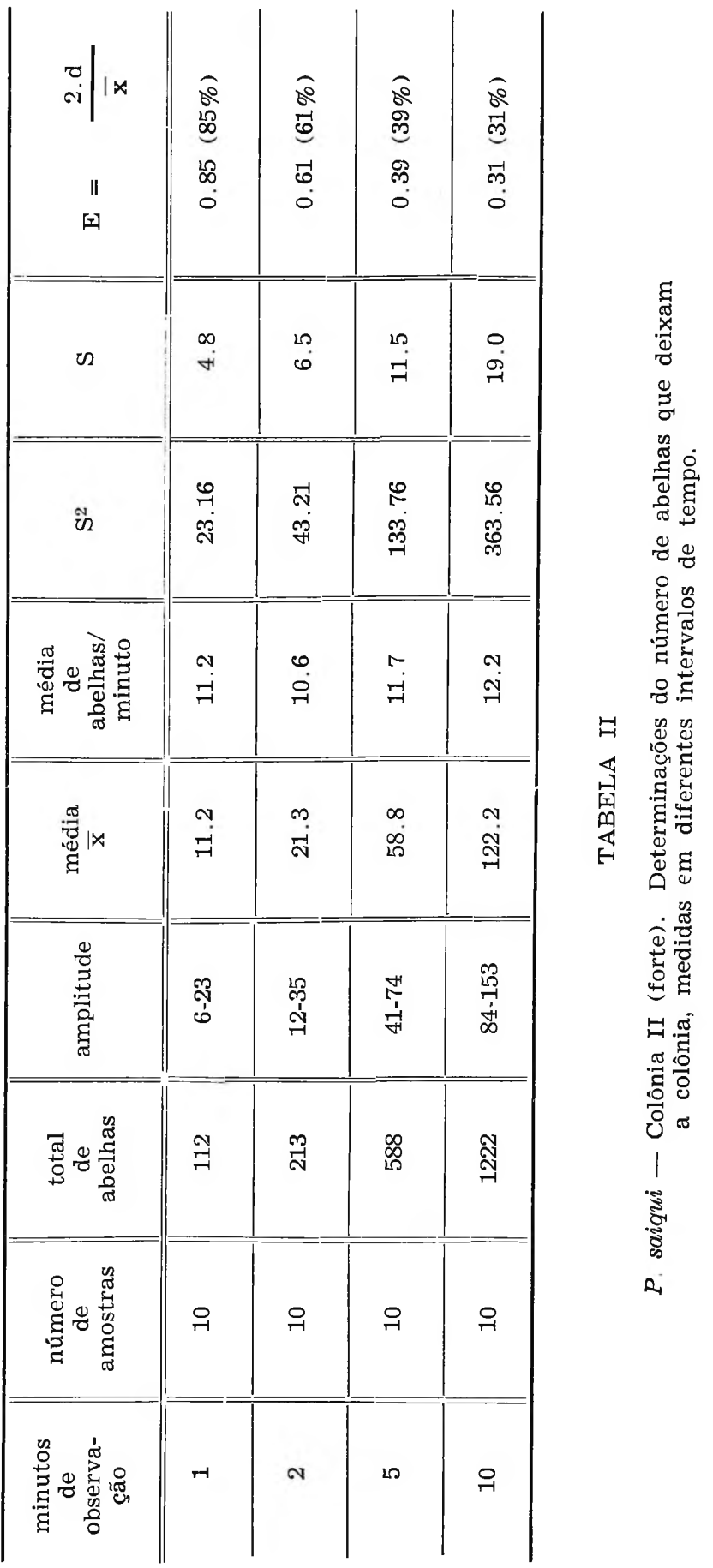




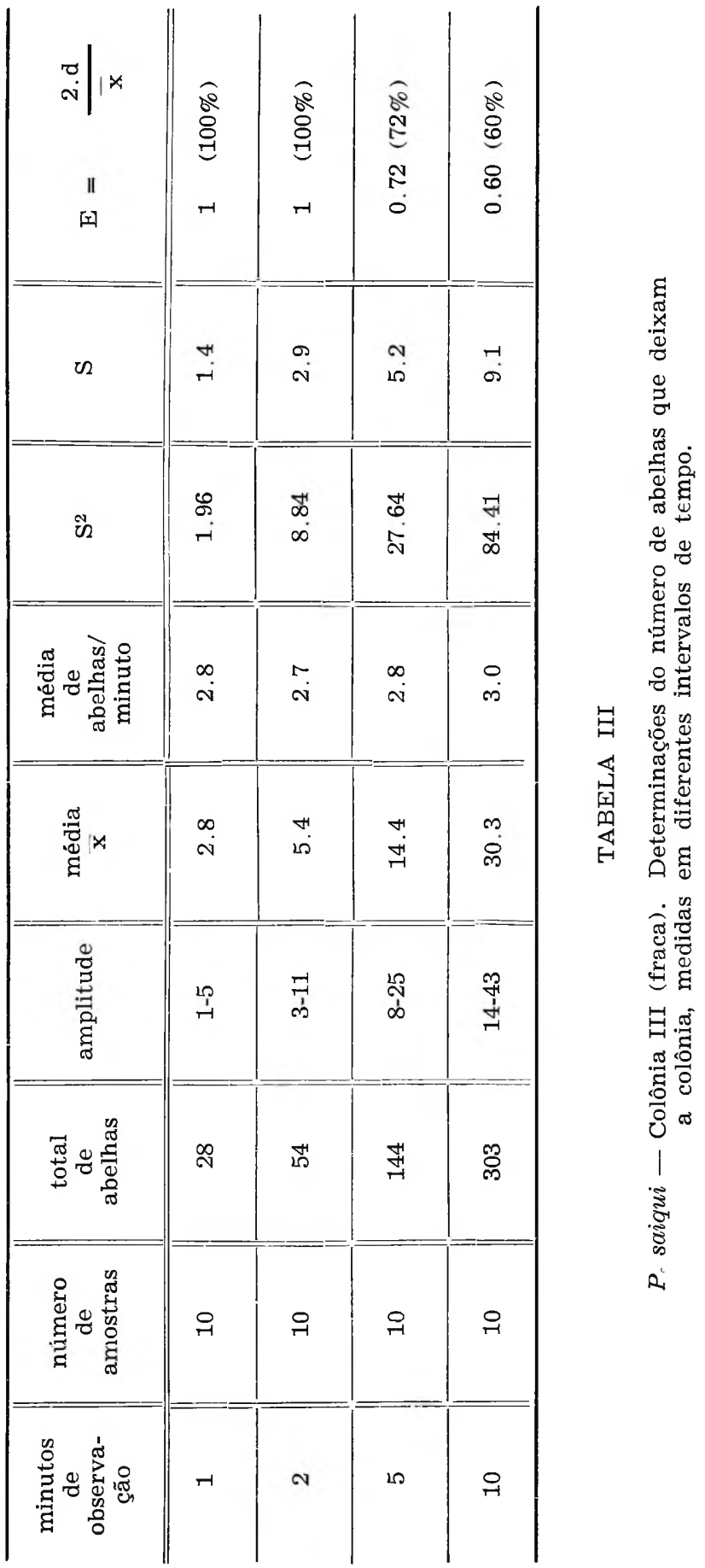




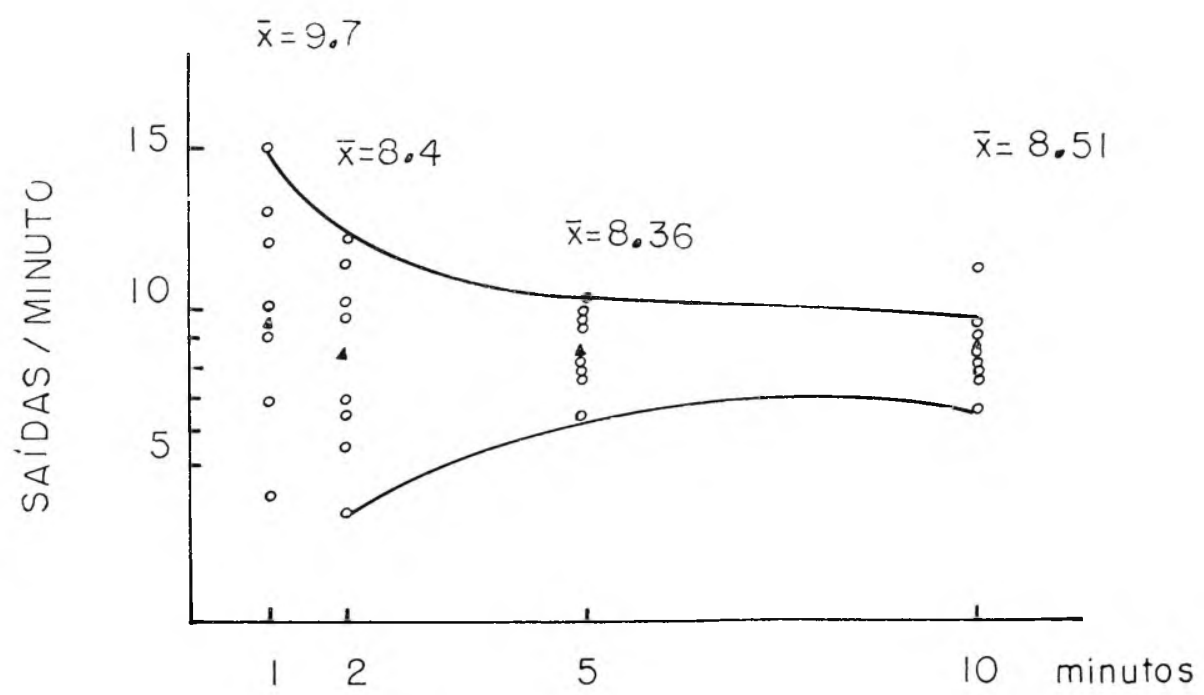

Gráfico $1-P$. saiqui. Colônia I. Número de abelhas que saem por minuto em diferentes intervalos de tempo.

Em relação às colônias fracas (Tabela III) há um erro bastante grande, mesmo em observações com duração de 10 minutos, o que indica que, nessas condições, o tempo de observação deverá ser aumentado.

Gary (1967b) trabalhou com Apis mellifera e verificou que, para esta espécie, 30 segundos de observação já eram suficientes para se avaliar as atividades da colmeia. Isto era de se esperar, uma vez que as colônias desta espécie apresentam um número muito grande de indivíduos (aproximadamente 8000 — Lindauer e Kerr, 1960) em relação à Plebeia saiqui cujas colônias fortes acredito possuem por volta de 3.000 abelhas.

\section{A G R A D E C I M E N T S}

A FAPESP pela concessão de bolsa de estudos (Biológicas 71/328) e ao Dr. Paulo Nogueira Neto por constantes estímulos e sugestões.

\section{REFERÊNCIAS BIBLIOGRÁFICAS}

BISHOP, O. N. (1966) - Statistics for Biology. Longmans, Green and Co. Ltd. Great Britain. 184 p. 
BODENHEIMER, R. S. \& BEN-NERYA, A. (1937) - One Year Studies on the Biology of the Honeybee in Palestine. Ann. Appl. Biol., 24:385-403.

GARY, N. E. (1967a) - Diurnal Variations in the Intensity of Flight-Activity from Honeybee Colonies. J. Ap. Res., 6(2):65-68.

(1967b) - A Method from Evaluating Honeybee Flight Activity at Hive Entrance. J. Econ. Entomol., 60(1):102-105.

LINDAUER, M. \& KERR, W. E. (1960) - Communication between the workers of Stingless Bees. Bee World, 41:29-41. 
